\title{
Messe: 2. IT \& Media in Darmstadt
}

Am 24. und 25. April findet die zweite IT \& Media in Darmstadt im darmstadtium statt. Ob Vertrieb, Produktion oder Warenwirtschaft, mittelständische Unternehmen möchten ihre Prozesse noch schlanker und effizienter gestalten. Auf der Darmstädter Messe IT \& Media zeigen rund 200 Aussteller, welche neuen Möglichkeiten es in diesem Bereich gibt. Zu den Highlights zählen in diesem Jahr die Task-Force des Bundeswirtschaftsministeriums zur IT-Sicherheit, sowie die KeyNote von Mario Ohoven, Präsident des Bundesverbands mittelständische Wirtschaft (BVMW) und Resident des europäischen Mittelstandverbands.

Michael Mattis, Geschäftsführer der AMC24 GmbH \& Co. KG und Veranstalter der IT\&Media 2013 erklärt: „Die Messe richtet sich an Geschäftsführer und IT-Entscheider, die in Kürze erfahren wollen, wie Sie ihre eigene IT-Infrastruktur verbessern können.“ Es lohne sich, betont Mattis, sich etwas Zeit für den Messebesuch zu nehmen, weil hier an einer Stelle gebündelt eine Vielzahl von Möglichkeiten für die Optimierung von Prozessen präsentiert und erklärt werden.

\section{Podiumsdiskussion}

Gespannt sein dürfen die Besucher, was der Präsident des Bundesverbands mittelständische Wirtschaft Mario Ohoven in seiner Keynote sagen wird. Mattis: „Wir freuen uns, dass dieser hochkarätige Wirtschaftsfachmann unsere Messe bereichern wird. "Darüber hinaus wird die Task Force des Bundeswirtschaftsministeriums beim Thema „IT-Sicherheit“ viele Fragen aufgreifen, die den Unternehmen unter den Nägeln brennen. Vorgesehen ist eine Podiumsdiskussion mit einer Abfrage im Plenum bei den Zuschauern.

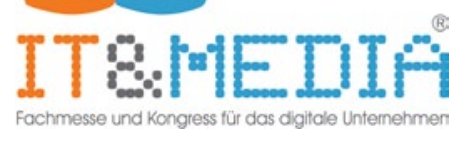

Die IT \& Media 2013 bietet Besuchern auf zwei Ebenen und auf über $4000 \mathrm{~m}^{2}$ inklusive einer Konferenz mit 46 Vorträgen alle Möglichkeiten um sich über optimale Prozessabläufe zu informieren.

\section{Marktplatz Cloud:}

Gerade für den Mittelstand können Cloud Anwendungen erhebliche Kostenvorteile bringen. Mit dem Marktplatz Cloud stellt die IT\&Media eine attraktive Plattform für Unternehmenslösungen aus der Cloud bereit. Zusammen mit einem Ausstellungsstand erhalten die Unternehmen automatisch auch einen Speakerslot auf dem Marktplatz Cloud.

Die Vorträge werden auf einer extra Seite in der Messezeitung explizit angekündigt, so dass sich die Besucher der Messe über die Lösungen und Themenangebote schnell und einfach informieren können. Der Marktplatz Cloud wird zudem mit besonderen Teppichen in eine wirkliche Wolke verwandelt.

Erstmals wird auf der IT \& Media 2013 in Kooperation mit dem Hessischen Rundfunk „hr-INFO“ der Anwender-Award verliehen. Zeit zum Kennenlernen und Netzwerken haben die Besucher beim Get-Together Messeabend in der ChilloutLounge mit Jazz-Band und Klaus Plönzke als Key-Speaker.

Die Öffnungszeiten der Messe sind am 24.04.2012 von 9:00 bis 17:30 Uhr und am 25.04.2012 von 9:00 bis 17:30 Uhr. Am 24. Findet im Anschluss an die Messe und Konferenz eine Abendveranstaltung statt zu der man sich auf der Website separat anmelden kann. Weitere Informationen unter: http:// www.itandmedia.de/

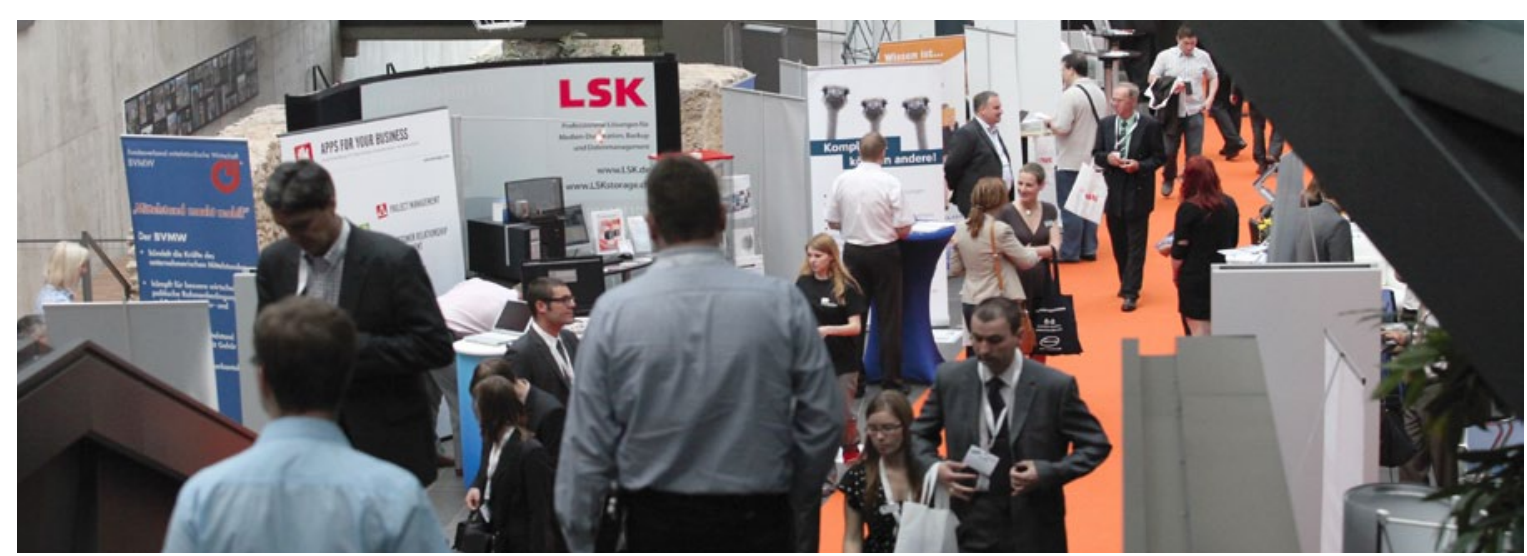

Reges Treiben auf der IT \& Media 2012 